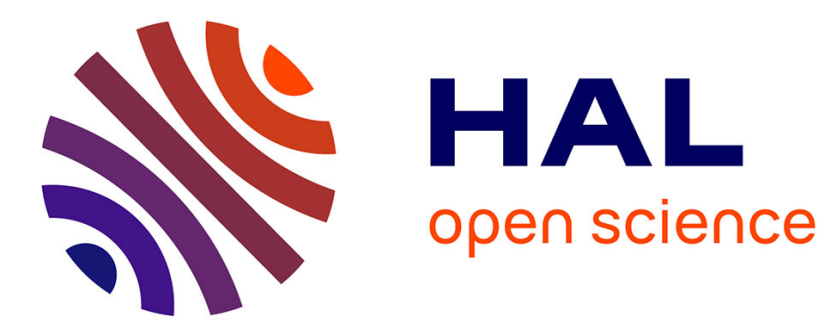

\title{
Gasification of char from wood pellets and from wood chips: Textural properties and thermochemical conversion along a continuous fixed bed
}

\author{
G. Teixeira, L. van de Steene, E. Martin, F. Gelix, Sylvain Salvador
}

\section{- To cite this version:}

G. Teixeira, L. van de Steene, E. Martin, F. Gelix, Sylvain Salvador. Gasification of char from wood pellets and from wood chips: Textural properties and thermochemical conversion along a continuous fixed bed. Fuel, 2012, 102, pp.514-524. 10.1016/j.fuel.2012.05.039 . hal-01688409

\author{
HAL Id: hal-01688409 \\ https://hal.science/hal-01688409
}

Submitted on 12 Mar 2018

HAL is a multi-disciplinary open access archive for the deposit and dissemination of scientific research documents, whether they are published or not. The documents may come from teaching and research institutions in France or abroad, or from public or private research centers.
L'archive ouverte pluridisciplinaire $\mathbf{H A L}$, est destinée au dépôt et à la diffusion de documents scientifiques de niveau recherche, publiés ou non, émanant des établissements d'enseignement et de recherche français ou étrangers, des laboratoires publics ou privés. 


\title{
Gasification of char from wood pellets and from wood chips: Textural properties and thermochemical conversion along a continuous fixed bed
}

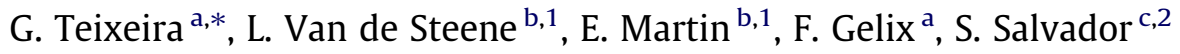 \\ a VERI-VEOLIA, Zone Portuaire, 291 Av. Dreyfous Ducas, 78520 Limay, France \\ ${ }^{\mathrm{b}}$ CIRAD-PERSYST, TA B42/16, 73 Rue JF Breton, 34398 Montpellier Cedex 5, France \\ ${ }^{\mathrm{c}}$ RAPSODEE, Ecole des Mines d'Albi-Carmaux, Route de Teillet, 81013 Albi CT Cedex 09, France
}

Keywords:

Char

Gasification

Fixed bed

Pellets

Compaction

\begin{abstract}
A B S T R A C T
In fixed bed gasifiers, the char bed gasification zone where char is converted into syngas plays a major role in terms of efficiency and control of the process. This zone is particularly complex as many phenom ena compete, i.e. heterogeneous and homogeneous chemical reactions, gas flow in porous medium and flow of solid particles.

This paper investigates the mechanical and thermochemical behavior of the char bed gasification zone and focuses particularly on bed compaction. To achieve this, a low density biomass char from wood chips and a high density one from wood pellets were gasified in a pilot scale continuous fixed bed reactor.

Measurements of profiles were taken along the char bed for temperature, gas species concentration, char composition, char bed density and char particle velocity using fine instrumentation and specific char and gas sampling techniques.

In our operating conditions, the char bed reactive zone is 3 times longer for chips $(45 \mathrm{~cm})$ than for pel lets $(16 \mathrm{~cm})$. We show that pelletization has no effect on: char bed compaction, final char conversion (about $95 \%$ ) and syngas quality $\left(16 \% \mathrm{H}_{2}\right.$ and $\left.13 \% \mathrm{CO}\right)$.

Finally, we discuss char bed compaction and the main phenomena that control it in order to propose a line of inquiry for modeling.
\end{abstract}

\section{Introduction}

The future is promising for the exploitation of biomass to convert lignocellulosic materials into useful energy, such as heat, electricity or liquid fuel [1]. Three main technologies are pro posed depending on the application: entrained flow, fluidized bed and fixed bed reactors. Staged gasifiers in the latter category

\footnotetext{
* Corresponding author. Tel.: +33130983294.

E-mail addresses: gabriel.teixeira@veolia.com (G. Teixeira), steene@cirad.fr (L. Van de Steene), franck.gelix@veolia.com (F. Gelix), salvador@mines-albi.fr (S. Salvador).

${ }^{1}$ Tel.: +33 4676165 22; fax: +33467616515.

2 Tel.: +335634930 26; fax: +33563493243.
}

have proven their potential for low and medium power electric ity production. Some commercial applications are available for wood chips. The success is largely due to the low tar content in the fuel gas produced. In such processes (Fig. 1), pyrolysis and char gasification stages take place in separate reactors. This enables the pyrolysis gases to be oxidized in a high temperature zone where efficient tar cracking occurs. Indeed, wood chips are first dried and pyrolyzed in the pyrolysis reactor. The char pro duced falls to the bottom of the gasification reactor where it is gasified by steam and carbon dioxide from the previous steps. The energy and part of the reacting gas are produced by the oxi dation of pyrolysis gases in the zone above the char bed.

The disadvantage of this technology is that it lacks flexibility in terms of the origin/type of biomass. Most operating processes are 


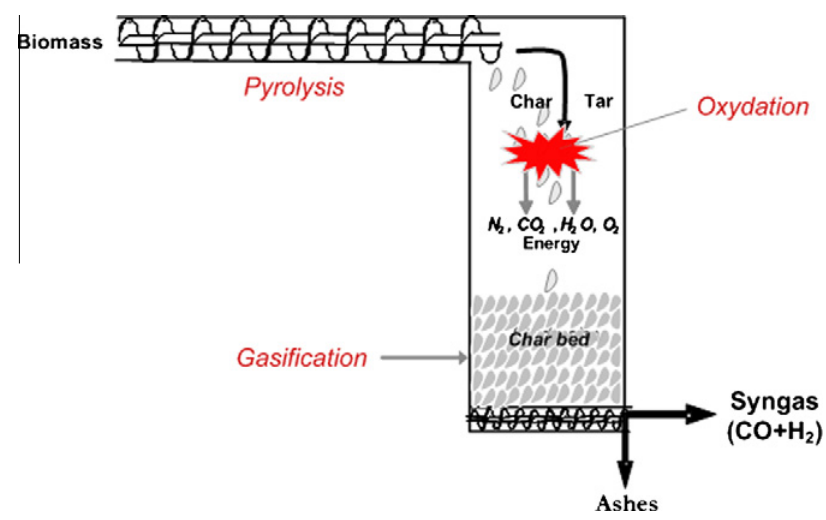

Fig. 1. Staged gasification principle.

only available for wood chips [2,3]. Staged reactors are unable to exploit fine or low density biomasses straw, rice husk, bagasse which represent by far the greatest potential worldwide [4]. The main problem concerns the considerable pressure drop of the char bed due to the compaction of this type of breakable bio mass at the bottom of the char gasification zone. This phenomenon may induce gas channeling across the solid bed and, thus, disrupt the process. Poor solid flow, low energy density and high ash con tent resulting from the use of this type of biomass in a staged fixed bed can lead to other serious technical problems.

Pelletization can be used to overcome most of the difficulties listed above because pellets have a high density, high mechanical resistance and standardized dimensions $[5,6]$. Moreover, biomass with a high ash content can be mixed with a different biomass with a lower ash content before pelletization. Over and above the tech nical advantages, pelletization has economic advantages in terms of transport, storage and logistics [7]. Thus, we conducted an inves tigation using wood pellets. Wood chips are included as the reference.

In a staged gasifier, the char is converted into syngas in the char gasification zone, where many phenomena compete, i.e. heteroge neous and homogeneous chemical reactions, gas flow in porous media and the flow of solid particles. There are very few biblio graphic references on specific investigations in this important field. Most studies concern general fixed bed processes with wood chips $[8,9]$ or biomass pellets [10 13] as feedstock. Moreover, experi mental measurements, such as temperature, carbon conversion and gas composition were only carried out at the outlet of the process.

Several authors conducted a finer characterization of the char bed by measuring temperature and gas species profiles [14 16] in order to determine the main transformations involved. Refer ence to previous studies is useful for predicting conversion and syngas composition. However, they do not describe the evolution of chemical and mechanical properties along the char bed. The pri mary reason for this is linked to the fact that little is known about the quality of the gasifying stream. The latter depends on previous steps: drying, pyrolysis and volatile matter oxidation. Secondly, the processes used are not generally designed to provide relevant information from inside the bed. Consequently, no bibliographic data is available on the evolution of the structural properties and the thermochemical conversion of a continuous char bed during gasification.

The Continuous Fixed Bed (CFiB) reactor presented and charac terized in a previous paper [17] was developed to meet this chal lenge. The aim of this research was to compare the mechanical and thermochemical behavior of a continuous char bed during the gasification of a low density biomass (wood chips) and a high density biomass (wood pellets). In order to achieve the objec tive, a detailed experimental study was conducted to measure: the evolution of bulk density/porosity, char velocity/residence time, carbon conversion, gas species composition and temperature.

The results obtained are of major importance and will help con structors design and optimize the processes using pelletized bio mass. It will also help researchers working on the validation/ development of CFD models.

\section{Materials and methods}

\subsection{Production and characterization of the wood chip char (WCC) and} wood pellet char (WPC)

The initial samples used consisted of maritime pinewood condi tioned in two different forms: chips from the Cevennes region (France) and pellets (DIN + quality) from the Landes region (France). Measurements were taken for humidity, ash, volatile matter and elementary composition in accordance with the AFNOR standards. Results (Table 1 ) show that volatile matter content is above $80 \%$ and the ash content is below $0.5 \%$ for both biomass packaging.

These feedstocks produced two chars for the present study using a screw pyrolysis reactor. The reactor consists of the pyroly sis unit of CIRAD's two stage gasifier, which was disconnected from the rest of the pilot. We used the pyrolysis reactor to ensure that the char was equivalent to that used in the char gasification zone of industrial two stage gasifiers. The pyrolysis unit is de scribed in detail elsewhere [18]. Briefly, it consists of a stainless steel cylinder with an external electrical heating system. The cylin der is horizontal and contains an endless screw.

Pyrolysis operating conditions are known to significantly influ ence the nature of the char produced [19]. The operating condi tions for the char production were as follows: residence time $1 \mathrm{~h}$; temperature $750{ }^{\circ} \mathrm{C}$; flow rate $15 \mathrm{~kg} \mathrm{~h}{ }^{1}$. Readers familiar with two stage gasifiers will notice that the pyrolysis temperature is higher than that recommended in gasifiers of this type. We inten tionally increased the temperature of pyrolysis to reduce residual volatile matter in the char because the latter would have compli cated our study (based on mass balance), which does not focus on tar behavior.

From $1000 \mathrm{~kg}$ of biomass, about $200 \mathrm{~kg}$ of char were produced for each biomass packaging in order to carry out the experiments. All the char produced was sieved to remove particles of less than $1 \mathrm{~mm}$. Fine particles are of no particular interest because they react very rapidly compared to larger particles. We removed them for predominantly practical reasons. Fine particles deposited on the conveyor belt can escape into the atmosphere during feeding, which may affect the mass balance.

Composition and properties of the char produced are presented in Table 1. It is important to note that the volatile matter content was less than $4 \%$ for both types of packaging. The characterization of the Wood Chip Chars (WCCs) is completed with the particle thickness distribution (Fig. 2): $80 \%$ mass range for particles of 0 $3.5 \mathrm{~mm}$ thickness. Regarding WCC dimensions, only the thickness is presented here as we have shown in a previous study that it was the critical dimension of the particle for the gasification pro cess [20]. The dimensions of the wood pellets received are stan dardized (6 $\mathrm{mm}$ average diameter). They sintered during pyrolysis to reach an average diameter of $4.2 \mathrm{~mm}$. Fig. 3 shows the two wood feedstocks and the two chars that were produced.

It is important to mention that the char produced from wood pellets demonstrated considerable mechanical resistance when handled compared to that from WCC. This aspect confirms the potential of the use of pellets in a gasifier. The risk of WPC disinte gration is negligible. 
Table 1

Composition and properties of maritime pine wood (chips and pellets) and prepared chars.

\begin{tabular}{|c|c|c|c|c|}
\hline & Wood chips & Wood pellets & Char chips & Char pellets \\
\hline \multicolumn{5}{|l|}{ Proximate analysis (wt\% dry basis) } \\
\hline Ash & 0.4 & 0.2 & 1.7 & 1.4 \\
\hline Volatile matter & 83.1 & 84.4 & 4.0 & 2.0 \\
\hline \multicolumn{5}{|l|}{ Ultimate analysis (wt\% dry basis) } \\
\hline C & 49.2 & 50.8 & 92.6 & 92.8 \\
\hline $\mathrm{H}$ & 6.3 & 6.4 & 1.0 & 1.3 \\
\hline $\mathrm{N}$ & $<0.1$ & $<0.1$ & 0.2 & 0.3 \\
\hline S & $<0.2$ & $<0.2$ & $<0.2$ & $>0.2$ \\
\hline LHV (MJ kg ${ }^{1}$ dry basis) & 18.6 & 19.6 & 33.4 & 33.1 \\
\hline Char bed bulk density $\left(\mathrm{g} \mathrm{cm}^{3}\right)$ & - & - & 0.13 & 0.37 \\
\hline Particle skeletal density $\left(\mathrm{g} \mathrm{cm}^{3}\right)$ & - & - & 1.27 & 1.34 \\
\hline Particle density $\left(\mathrm{g} \mathrm{cm}^{3}\right)$ & - & - & 0.33 & 0.66 \\
\hline Particle porosity $(-)$ & - & - & 0.74 & 0.51 \\
\hline Particle average thickness (mm) & - & - & 5.2 & 4.2 \\
\hline
\end{tabular}

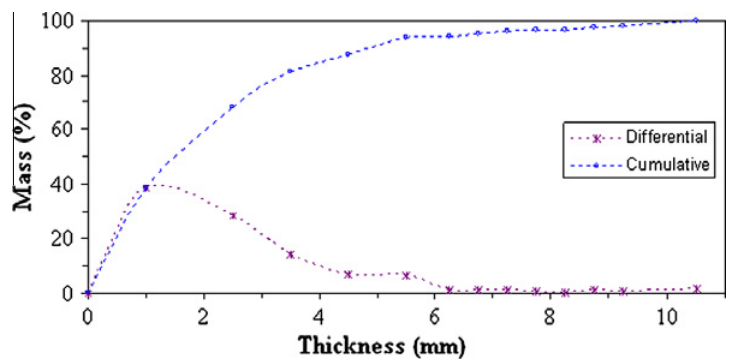

Fig. 2. Particle thickness distribution of the wood char chips.

\subsection{Experimental apparatus: the continuous fixed bed reactor}

The Continuous Fixed Bed reactor $(C F i B)$ was designed and built at CIRAD (Fig. 4). The gasification chamber consists of a 310 type refractory steel tube ( $200 \mathrm{~mm}$ i.d., $1600 \mathrm{~mm}$ long) surrounded by refractory wool insulation.
The gasifying stream is generated by two propane burners (c) and a superheated steam generator (d). Propane, air and water flow rates are accurately adjusted by flow meters/controllers so that the gasifying stream can be carefully controlled in terms of gas species concentration and temperature after combustion. The char mass flow rate is regulated by a conveyor belt (a). During the operation, the bed height is maintained at a constant level with the removal of the solid residue at the bottom (e), which is adjusted accord ingly. The instrumentation of the apparatus and the control of the process are important points that have already been described and discussed in a previous paper [17].

\subsection{Original char bed characterization}

The instrumentation of the equipment is key point. Sampling and measuring probes are located at $100 \mathrm{~mm}$ intervals along the length of the char bed allowing direct analysis of temperature, pressure and gas composition, including condensates. The profiles

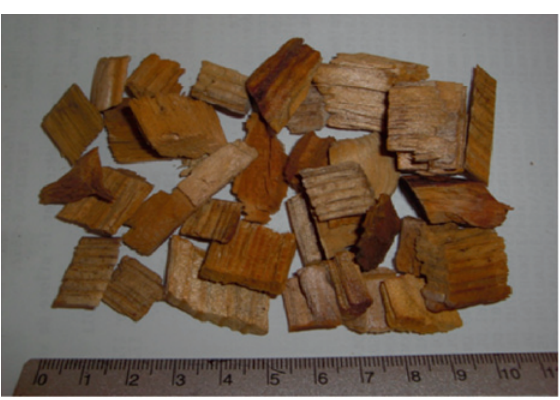

WC

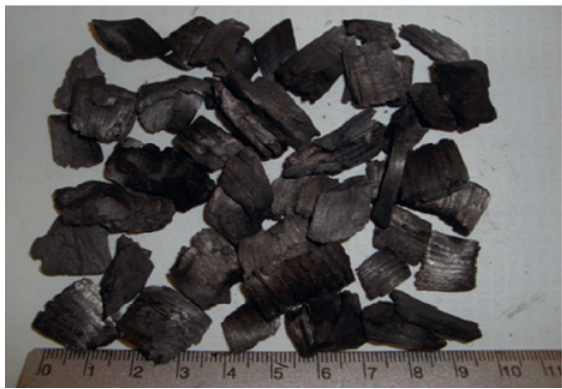

WCC

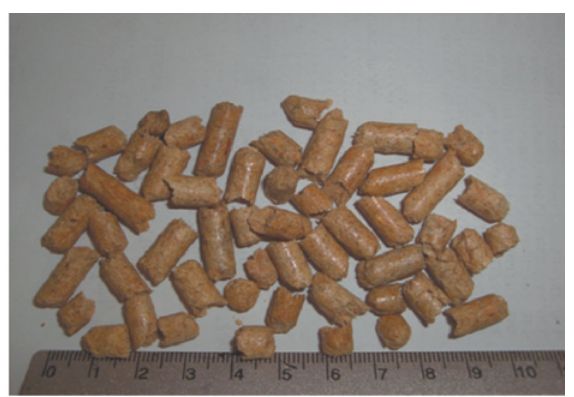

WP

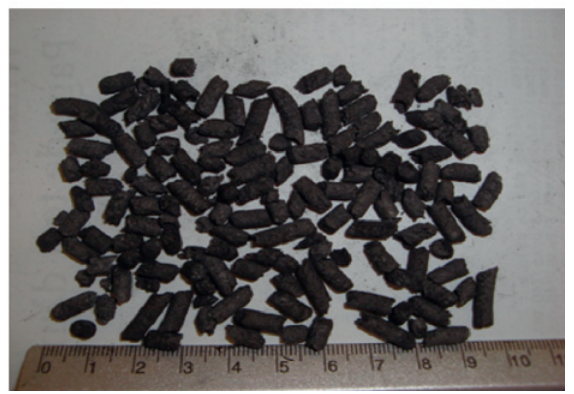

WPP

Fig. 3. Picture of wood and char from chips (a) and pellets (b). 


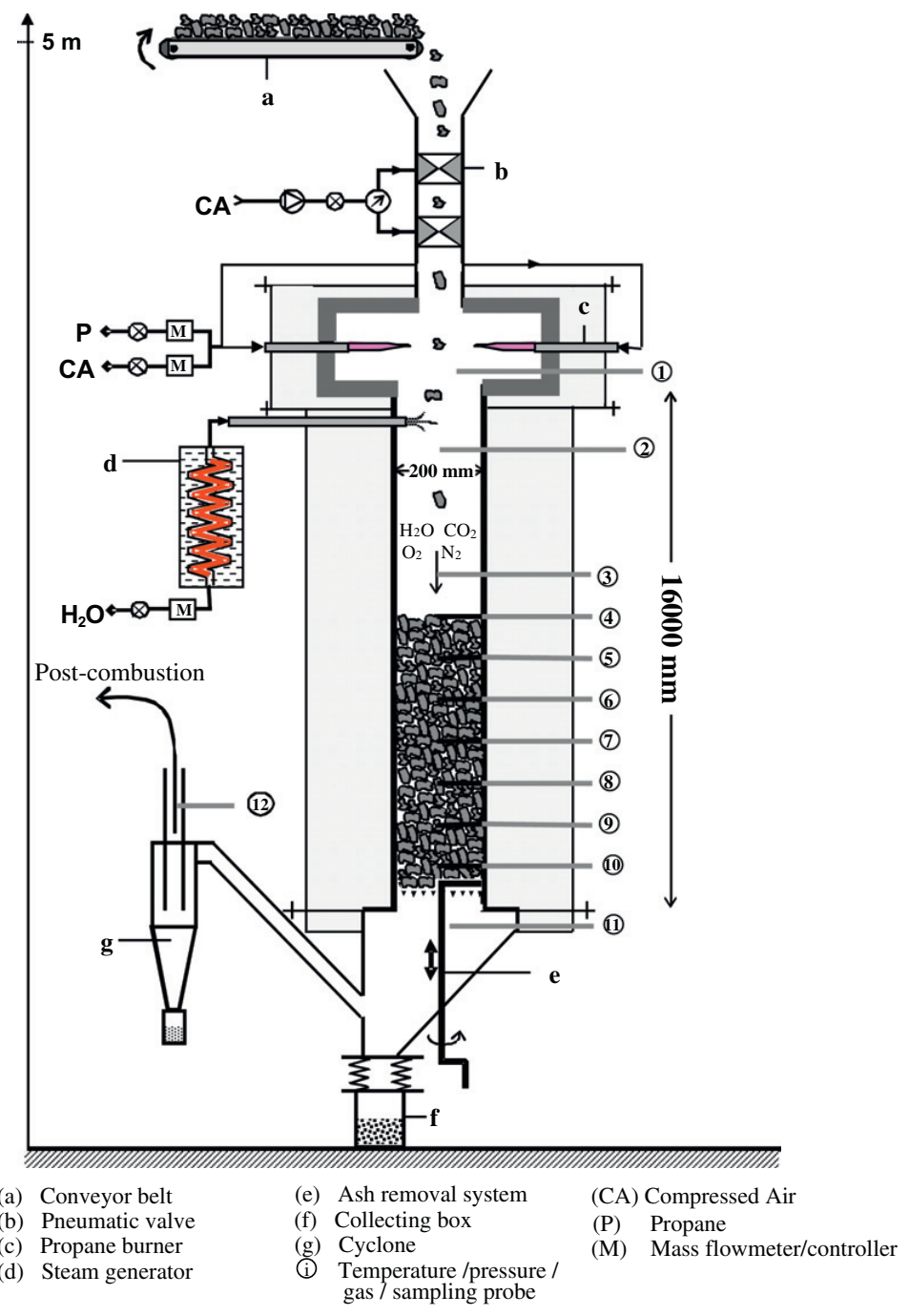

Fig. 4. The CFiB Reactor.

obtained are very useful for characterizing the char bed during gasification.

Given the complexity of the phenomena involved, we did our utmost to improve our apparatus' potential in order to obtain de tailed information on char behavior along the bed in terms of: con version, density and velocity, in particular. These improvements are described in the following sections.

\subsubsection{Char bed sampling}

Char bed sampling principle consists of quenching and cooling the reactor and then collecting the bed in several horizontal layers. It is possible to establish profiles of bulk density and char ash con tent along the bed.

Char bed sampling layer by layer is not possible using the re moval system at the bottom of the reactor for two reasons: (i) the non homogeneous flow of char particles along the reactor when rapid removal is in operation may mix the different layers and (ii) char bed bulk density cannot be measured this way be cause the volume of the removed layer (as it is inside the reactor) is not accessible.

Consequently, we developed an accurate sampling solution, which consists of sampling char layers from the top of the reactor with a suction system.
Getting into more details, the procedure was as follows.

When the experiment is stopped, the bed temperature varies from $1050^{\circ} \mathrm{C}$ at the top to $700{ }^{\circ} \mathrm{C}$ at the bottom. Therefore, the char bed needs to be quenched in order to stop the reactions. A flow of $2001 \mathrm{~min}^{1}$ of nitrogen was injected for $30 \mathrm{~min}$ through the two propane burners leading to a decrease in the bed temperature to below $700{ }^{\circ} \mathrm{C}$. Then a flow of $51 \mathrm{~min}{ }^{1}$ of nitrogen is maintained for at least $24 \mathrm{~h}$ in order to cool down the reactor to below $100{ }^{\circ} \mathrm{C}$ before it can be opened.

Next, for char collection, a suction system is used to sample the char bed layer by layer. On a practical level, the suction pipe is positioned at the surface of the bed and moved horizontally over the surface while maintaining a constant vertical position. The suc tion flow rate was adjusted so that it was high enough to collect particles close to the pipe and low enough to avoid attracting small particles from lower layers. Then, the new bed height was mea sured and compared to that before suction to give the height of the collected layer. Char layers were about 5 and $3 \mathrm{~cm}$ thick for WCC and WPC, respectively, because WCC has a lower density.

With this technique, it is important to ensure that no fine par ticles (ash, in particular) go through the collecting bag. Conse quently, we conducted a suction trial on various previously prepared char samples of different particle size and ash content 
in order to check that the mass of char collected was the same as the mass before suction. We also checked to see if the ash contents before and after suction were similar to determine whether most of the fine ash had been trapped.

The bed sampling is also used to estimate profiles of char veloc ity. To this purpose, solid tracers were fed into the reactor at differ ent times. These tracers were then located in the bed during sampling technique. Six tracers were injected at $4 \mathrm{~h}, 3 \mathrm{~h}, 2 \mathrm{~h}, 1 \mathrm{~h}$, $30 \mathrm{~min}$, and $15 \mathrm{~min}$, respectively, before quenching the experi ment. Each tracer is composed of three ceramic pieces $(15 \times 8 \times 3 \mathrm{~mm})$ of about $0.8 \mathrm{~g} \mathrm{~cm}{ }^{3}$ density, which are fed into the reactor together. The height of each tracer is calculated as the average collection height for the three ceramic pieces. Velocity can be calculated from the derivation of residence time as a func tion of the height in the reactor.

The size of the tracers has to be large enough in order to facili tate their localization and collection in the char bed. It is likely that the tracers used follow char particle movement given the low dis placement velocity of the bed: less than $5 \mathrm{~mm} \mathrm{~min}{ }^{1}$ as shown later.

Using the collected data, the profile of char conversion can be calculated following three different approaches using the method ology discussed in Section 2.3.2 below.

\subsubsection{Determining profiles of conversion}

Char bed conversions were calculated using three separate methods as described below.

\section{a. From ash content in char}

The first method, known as the ash tracer method, is based on a comparison of the ash content in the initial char and in the char bed sample [21]. The conversion is given as follows:

$X^{\text {ash }} \frac{1 C_{\mathrm{ash}}^{\mathrm{char}, 0} / C_{\mathrm{ash}}^{\mathrm{char}}}{1 C_{\mathrm{ash}}^{\mathrm{char}, 0}}$

$C_{\mathrm{ash}}^{\mathrm{char}, 0}$ and $C_{\mathrm{ash}}^{\mathrm{char}}$ are the ash content (wt\% dry basis) in the initial char and in the collected solid char residue, respectively.

b. From char bed density and char velocity.

The conversion was also calculated using the char bed bulk den sity and the velocity of char particles as follows:

$$
\begin{array}{ccccccc}
X^{\rho, v} & \frac{m_{C, 0}}{m_{C, 0}} m_{C} & & \left.\frac{\left(m_{\text {Char }, 0}\right.}{m_{\text {ash }}}\right) & \left(m_{\text {Char }}\right. & \left.m_{\text {ash }}\right) \\
m_{\text {Char }, 0} & m_{\text {ash }} & \\
1 & \frac{\rho_{\text {char }}}{\rho_{\text {char }}^{0}} v_{\text {char }} S & v_{\text {char }}^{0} S & m_{\text {ash }} &
\end{array}
$$

$\dot{m}_{\text {Char }, 0}$ and $\dot{m}_{\text {Char }}$ are the mass flow rates $\left(\mathrm{kg} \mathrm{s}^{1}\right)$ of the char, respec tively at the inlet and in the bed. $\dot{m}_{c, 0}$ and $\dot{m}_{c}$ are the carbon mass flow rates $\left(\mathrm{kg} \mathrm{s}^{1}\right) \cdot \dot{m}_{\text {ash }}$, is the mass flow rate of ash $\left(\mathrm{kg} \mathrm{s}^{1}\right)$. This flow is constant all along the bed. $\rho_{\text {char }}^{0}$ and $\rho_{\text {char }}$ are the bulk densi ties $\left(\mathrm{kg} \mathrm{m}^{3}\right)$ of the initial char and the sampled char. They were calculated as the ratio of the mass in a layer to the volume of the layer. $v_{\text {char }}^{0}$ and $v_{\text {char }}$ are the velocities $\left(\mathrm{m} \mathrm{s}^{-1}\right)$ of char, at the inlet and in the bed. $S$ is the reactor section $\left(\mathrm{m}^{2}\right)$.

Density and velocity were calculated as described previously (Section 2.3.1).

\section{c. From the carbon molar balance.}

Using the carbon molar flow rates entering the reactor (char and $\mathrm{CO}_{2}$ ), it is possible to calculate the char bed conversion along the entire bed with the carbon molar flow rates in the gas phase $\left(\mathrm{CO}_{2}, \mathrm{CO}\right.$ and $\left.\mathrm{CH}_{4}\right)$, as follows:
$X^{\mathrm{C}} \quad \frac{\left(n_{\mathrm{C}}^{0} \quad n_{\mathrm{C}}\right)}{n_{\mathrm{C}}^{0}} \quad \frac{n_{\mathrm{CO} 2}+n_{\mathrm{CO}}+n_{\mathrm{CH} 4} \quad n_{\mathrm{CO} 2}^{0}}{n_{\mathrm{C}}^{0}}$

where $\dot{n}_{i}^{0}$ and $\dot{n}_{i}$ are the molar flow rates $\left(\mathrm{mol} \mathrm{s}^{1}\right.$ ) of gas species $i$ ( $i \mathrm{CO}_{2}, \mathrm{CO}$ or $\mathrm{CH}_{4}$ ) in the gasifying stream and the gas phase, respectively.

$\dot{n}_{C}^{0}$ and $\dot{n}_{C}$ are the molar flow rates $\left(\mathrm{mol} \mathrm{s}^{-1}\right)$ of carbon in the char fed into the reactor and in the bed, respectively.

\section{Results and discussion}

\subsection{Evolution of the measured parameters along the bed}

The experiments were performed in triplicate for each feed stock in order to show the reliability of the results obtained with the new char bed sampling technique. Table 2 shows the operating conditions of the experiments which have been adjusted to fit with industrial gasifiers. The presence of oxygen is necessary here to al low char oxidation in the char bed; this provides an energy surplus required by the endothermic reactions of char gasification by $\mathrm{H}_{2} \mathrm{O}$ and $\mathrm{CO}_{2}$. Additionally, in two stage gasifiers, it is likely that resid ual oxygen is present at the char bed inlet because of a bad mixing between pyrolysis gases and air in the oxidation zone. We also be lieve that the presence of $\mathrm{O}_{2}$ is a necessity to provide more energy in the char bed in order to reach a complete conversion.

In Fig. 5, we plotted the results from the Wood Chips Char (WCC) experiments on the left and from Wood Pellet Char (WPC) on the right. Results show good repeatability for the experiments, confirming the reliability of the char sampling technique that we developed. The few differences observed are discussed later.

The two graphs at the top of Fig. 5 compare the profiles of char bed density for WCC and WPC using the same full scale. Initial char bed density was measured on the feedstock before loading the reactor with $127 \mathrm{~kg} \mathrm{~m}^{3}$ and $370 \mathrm{~kg} \mathrm{~m}^{3}$ for WCC and WPC, respectively. For each feedstock, bulk density decreases rapidly along the first $5 \mathrm{~cm}$ of the bed, and then remains approximately constant at about $68 \mathrm{~kg} \mathrm{~m}^{3}$ for WCC and $170 \mathrm{~kg} \mathrm{~m}^{3}$ for WPC. The total decrease in bulk density is about $46 \%$ of the initial value for WCC and 55\% for WPC. The density of the bed is affected by sev eral phenomena, including mass loss due to chemical reactions, as well as the change in the particles' external diameter and fragmen tation. We will discuss these results further in the sequel of the paper.

Table 2

\begin{tabular}{|c|c|}
\hline Parameters & Experiment \\
\hline \multicolumn{2}{|l|}{ Reacting gas } \\
\hline $\mathrm{H}_{2} \mathrm{O}$ & $\begin{array}{l}28 \% \\
3.2 \mathrm{~mol} \mathrm{~min} 1\end{array}$ \\
\hline $\mathrm{CO}_{2}$ & $\begin{array}{l}8.2 \% \\
0.9 \mathrm{~mol} \mathrm{~min} 1\end{array}$ \\
\hline $\mathrm{O}_{2}$ & $\begin{array}{l}2.7 \% \\
0.3 \mathrm{~mol} \mathrm{~min} 1\end{array}$ \\
\hline $\mathrm{N}_{2}$ & $\begin{array}{l}61.1 \% \\
7.0 \mathrm{~mol} \mathrm{~min}\end{array}$ \\
\hline Solid char & $28 \mathrm{gmin}^{1}$ \\
\hline \multicolumn{2}{|l|}{ Molar ratios } \\
\hline $\mathrm{H}_{2} \mathrm{O} / \mathrm{C}$ & 1.5 \\
\hline $\mathrm{CO}_{2} / \mathrm{C}$ & 0.4 \\
\hline $\mathrm{O}_{2} / \mathrm{C}$ & 0.1 \\
\hline Temperature & $1028^{\circ} \mathrm{C}$ \\
\hline Gas velocity in free board & $0.7 \mathrm{~m} \mathrm{~s}^{1}$ \\
\hline Total pressure & $1.0 \mathrm{~atm}$. \\
\hline Ash removal period & $10 \mathrm{~min}$ \\
\hline Bed height & $650 \mathrm{~mm}$ \\
\hline
\end{tabular}

Operating conditions for WCC and WPC experiment. 

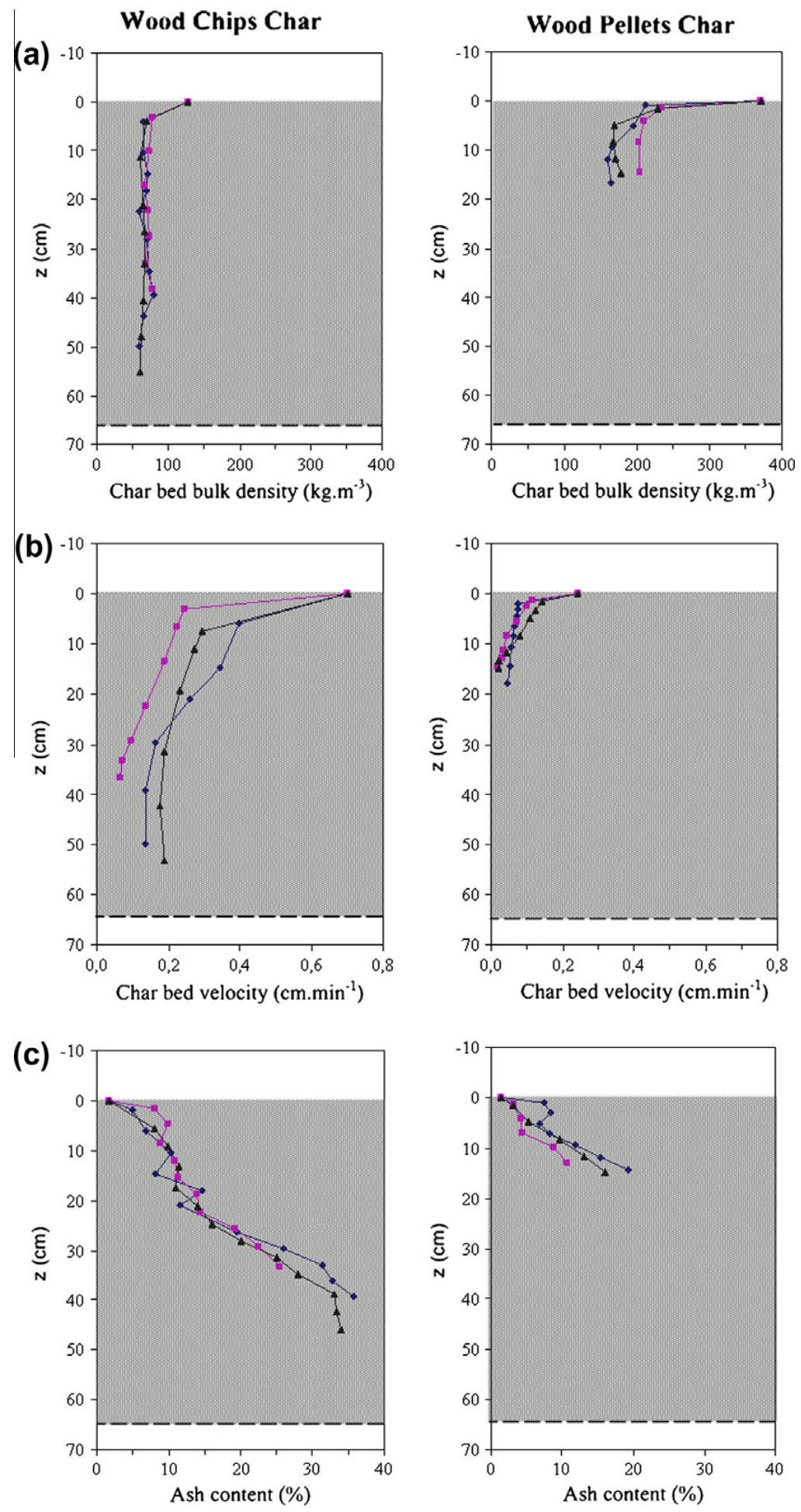

Fig. 5. Profiles of char bed bulk density (a), char velocity (b) and ash content (c) for chips and pellets experiments.

The second pair of graphs (Fig. 5b) compares the velocity of the two char beds using the same full scale. Velocity profiles were ob tained over about $47 \mathrm{~cm}$ for WCC and only $16 \mathrm{~cm}$ for WPC. This dif ference is due to WPC's very low velocity: the first tracers that were injected $4 \mathrm{~h}$ before quenching the experiment were collected at only about $16 \mathrm{~cm}$ from the top of the bed. The total char resi dence time in the bed can be estimated at over $17 \mathrm{~h}$. The reactor could have operated for a longer period of time. However, no addi tional information would have been obtained because char does not react below the active zone $(47 \mathrm{~cm}$ and $16 \mathrm{~cm}$ ) as we show la ter. At this point of the paper, the longer zone for a WCC bed can be explained by its higher volumetric flow rate. Indeed, the mass flow rates of the two chars are similar $\left(28 \mathrm{~g}\right.$ min $\left.{ }^{1}\right)$ but initial bulk den sities are very different ( 0.13 for WCC and 0.37 for WPC). We will 
see in the sequel of the paper that this first explanation is too sim plistic as many other mechanical and chemical phenomena that influence char bed compaction have to be considered when dis cussing about char bed velocity.

The poor repeatability for the velocity profiles is attributed to the heterogeneity of the char bed flow in a horizontal section: the three ceramic pieces that were loaded together were not re trieved in the same layer during sampling. The dispersion of results is greater for WCC because (i) the char velocity is higher and (ii) layers of $5 \mathrm{~cm}$ thickness were collected compared to $3 \mathrm{~cm}$ for WPC.

The major velocity drop occurs in the first $6 \mathrm{~cm}$ for WCC and the first $2 \mathrm{~cm}$ for WPC. This corresponds to a decrease of about $57 \%$ and $47 \%$ of their initial value, respectively. Below the top zones, the de crease in velocity is small although it does occur in both cases.

The last pair of graphs at the bottom of Fig. 5 compares ash con tent along the two char beds. The initial ash content measured for the feedstock before feeding the reactor was $1.76 \%$ and $1.42 \%$ (wt\% dry basis) for WCC and WPC, respectively. For each feedstock, ash content increases constantly until 39 and $15 \mathrm{~cm}$ for WCC and WPC, respectively. It is important to remember that the total conversion of carbon would lead to $100 \%$ ash content. But the relation between ash content and conversion is not linear; as an example a WCC con taining $50 \%$ ash is converted to $98.2 \%$.

In Fig. 6, we plot results from online analysis, i.e. the concentra tion of gas species and temperature along the bed using the aver age of the three repeatability experiments.

The two graphs at the top of Fig. 6 compare the concentration of $\mathrm{CO}_{2}, \mathrm{H}_{2} \mathrm{O}, \mathrm{CO}, \mathrm{H}_{2}, \mathrm{CH}_{4}$ and $\mathrm{N}_{2}$ for WCC on the left and for WPC on the right. In both cases, the amounts of $\mathrm{H}_{2}$ and $\mathrm{CO}$ in the first $10 \mathrm{~cm}$ are about $90 \%$ of their final values. The amount of $\mathrm{O}_{2}$ has fallen to zero. These variations in gas fractions indicate the presence of a highly reactive $\mathrm{H}_{2} \mathrm{O}$ gasification zone at the top of the bed. In addi tion, oxygen consumption shows that combustion also occurs in the top zone. Despite the very low\% of $\mathrm{O}_{2}$, this indicates that the energy produced by the exothermic char oxidation reaction just occurs at the very top of the bed.

It is important to note that the $\mathrm{CO}_{2}$ concentration remained rel atively constant along the bed. In fact, several reactions influence the $\mathrm{CO}_{2}$ concentration, particularly: the Boudouard reaction, which consumes $\mathrm{CO}_{2}$; and the char combustion and water gas shift reac
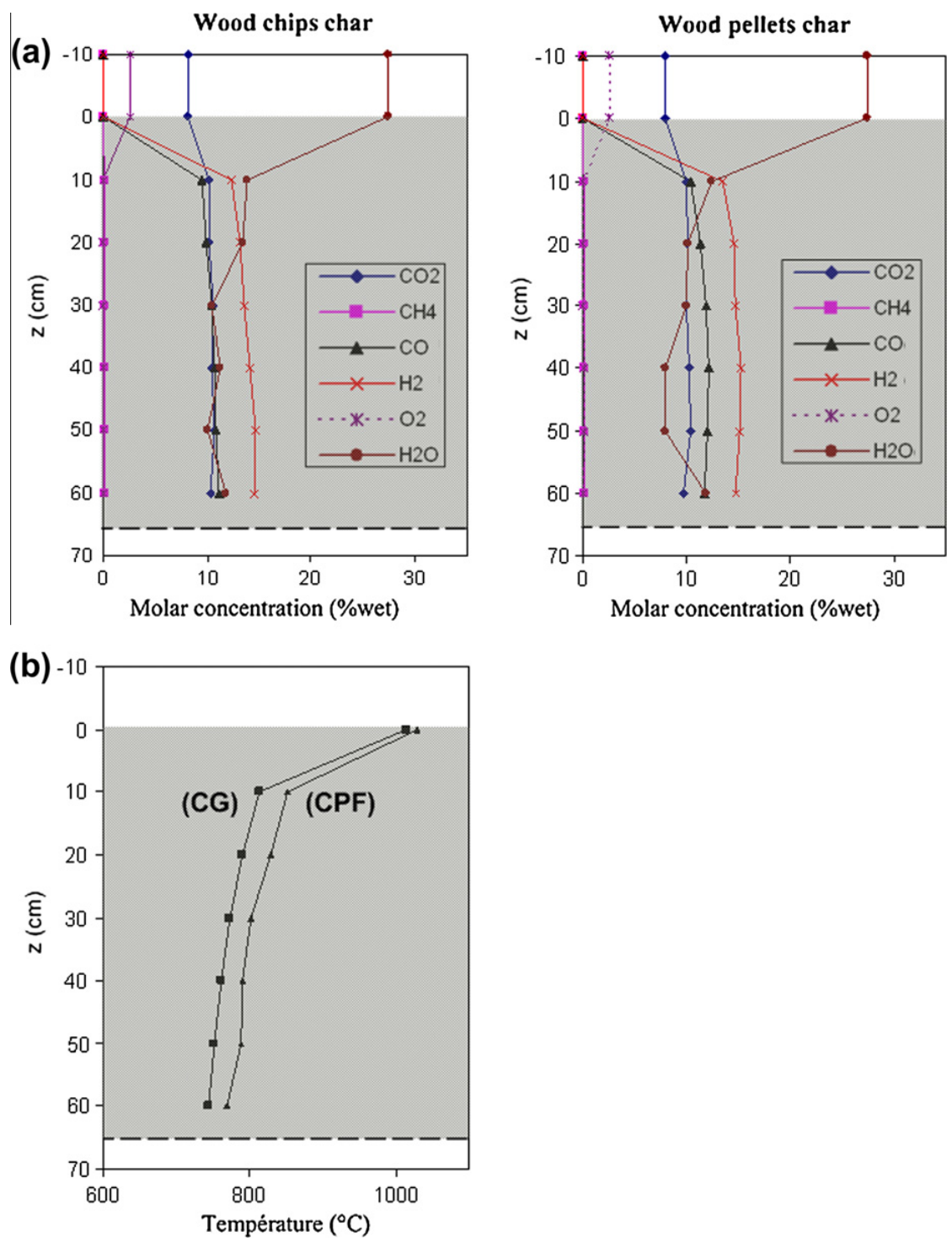

Fig. 6. Average molar concentrations of gas species (a) and average temperature (b) along the bed for WCC and WPC. 
tions, which produce $\mathrm{CO}_{2}$ [17]. Thus, it appears that production and consumption cancel each other out.

Moreover, the higher increase of $\mathrm{CO}$ and $\mathrm{H}_{2}$ in the first $10 \mathrm{~cm}$ of the bed for WPC is logically due to the longer residence time be cause the char is denser. However, the difference between the two feedstocks is not apparent at the outlet of the reactor. This can be explained by an energy balance: in both cases, a similar car bon mass flow and a similar gas flow are introduced in the system. The reactions stop when the temperature is low. As all $\mathrm{O}_{2}$ is con sumed in both cases, the progress of carbon gasification by $\mathrm{H}_{2} \mathrm{O}$ is similar and leads to similar $\mathrm{H}_{2}$ and $\mathrm{CO}$ contents (gases produced). We observed that biomass packaging does not induce any differ ence in syngas quality. In both cases, the syngas contained about $17 \%$ vol. $\mathrm{H}_{2}, 13 \% \mathrm{CO}, 11.3 \% \mathrm{CO}_{2}, 12 \% \mathrm{H}_{2} \mathrm{O}$ and $0.2 \% \mathrm{CH}_{4}$.

The graph at the bottom of Fig. 6 compares the temperature profile inside the two char beds. In the first $10 \mathrm{~cm}$, the bed temper ature decreases to $850^{\circ} \mathrm{C}$ and $810^{\circ} \mathrm{C}$ for WCC and WPC, respec tively and decreases slowly through the rest of the bed. This result confirms the presence of a highly reactive zone in the top of the bed where endothermic reactions of char gasification by $\mathrm{H}_{2} \mathrm{O}$ and $\mathrm{CO}_{2}$ are predominant. Below this zone, the low tempera ture slows down the endothermic gasification reaction by $\mathrm{H}_{2} \mathrm{O}$ and, consequently, slows down the decrease of bed temperature.

\subsection{Char conversion profiles}

The original results obtained for the char conversion along the bed from the three different approaches can now be examined.

Fig. 7 compares the conversion profiles for the two chars. Each graph shows three conversion profiles, calculated from the three methods presented in Section 2.3.2, i.e. using the profiles presented in Figs. 5 and 6. Each conversion profile shows an average conver sion value calculated from the three repeatability experiments.

Whatever the feedstock, the three methods provided very com parable results.

First of all, we observed that experimental points were not ob tained before $62 \%$ and $69 \%$ of conversion for WPC and WCC, respec tively. This can be explained by the fact that these conversion levels are reached very rapidly, at only 1 and $3 \mathrm{~cm}$ from the char bed surface. The graphs show that in the first $10 \mathrm{~cm}, 80 \%$ of conver sion is reached for WCC and $85 \%$ for WPC. The difference can be attributed to the longer residence time for WPC in this zone: about 3 times longer in relation to particle velocity (Fig. 5b).

Below this zone, the char conversion increase is low: this is attributed to low temperatures and the lower $\mathrm{H}_{2} \mathrm{O}$ content in the gas phase. Char conversion progresses in both cases to about $95 \%$. The final conversion is reached at about $20 \mathrm{~cm}$ for WPC and at over $50 \mathrm{~cm}$ for WCC because char velocity is higher. No reaction occurs below these zones: reactor length could be reduced.

\subsection{Discussion on char bed compaction during gasification}

In industrial gasifiers, the compaction of the char bed is a major determining factor in terms of the design and operation of the pro cess. Indeed, when compaction occurs the char residence time in creases and the bed porosity decreases. These changes have a direct impact on the process' efficiency (carbon conversion) and control (pressure drop).

Compaction is the consequence of a number of coupled chemi cal and mechanical phenomena, which are not generally consid ered in the existing models. In this section, we discuss the phenomena responsible for compaction in both a WCC bed and a WPC bed, on the basis of our experimental results. Our objective is to help improve gasifier models.

Compaction was clearly observed in our experiments. It is shown by the decrease in velocity along the char bed conversion, for both char beds. In order to quantify this phenomenon further, we propose defining compaction as the ratio between char veloci ties at the surface of the bed and at different locations within the bed in the following equation:

C $\frac{v_{\text {char }}^{0}}{v_{\text {char }}}$

As a starting point, we consider two ideal situations where compac tion is controlled only by the chemical conversion of char particles. Fig. 8 shows both these situations, which are traditionally used to model reacting beds. Either a uniform conversion within each par ticle (Fig. 8a) or a surface conversion (Fig. 8b) is considered. In the
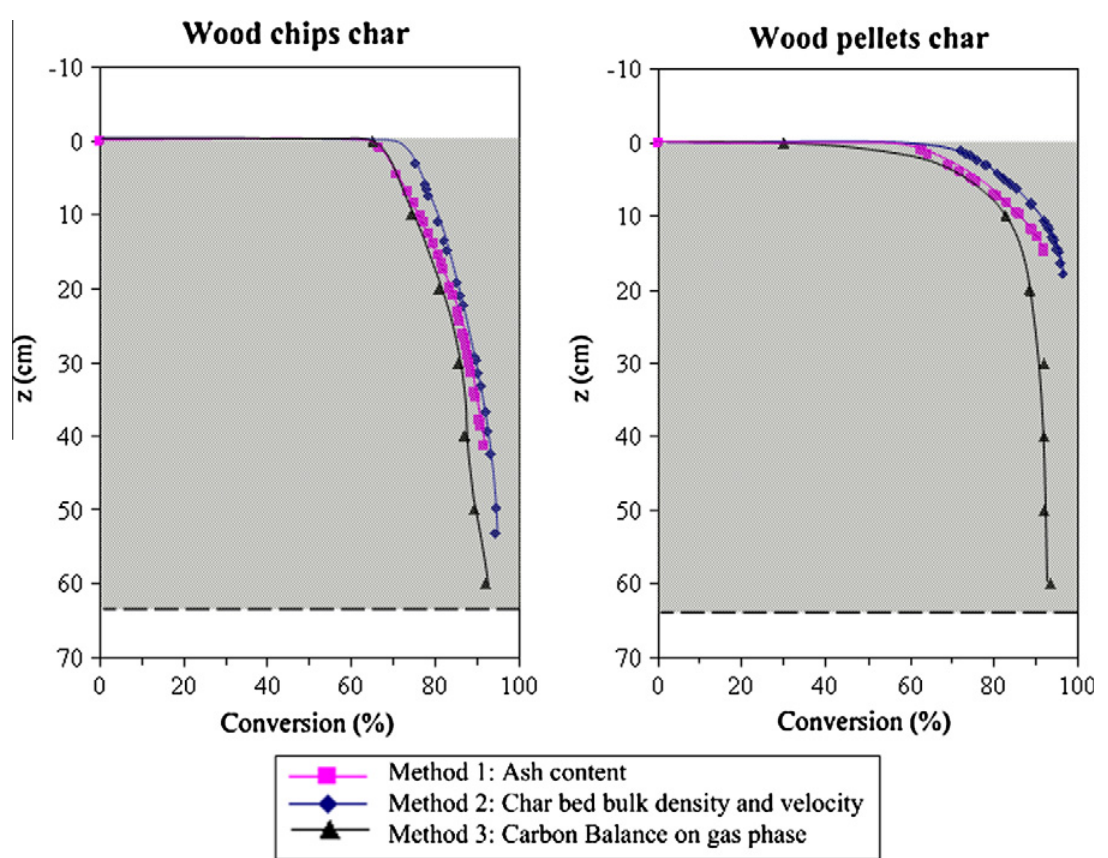

Fig. 7. Profiles of char bed conversion along the bed for WCC and WPC. 
(a)
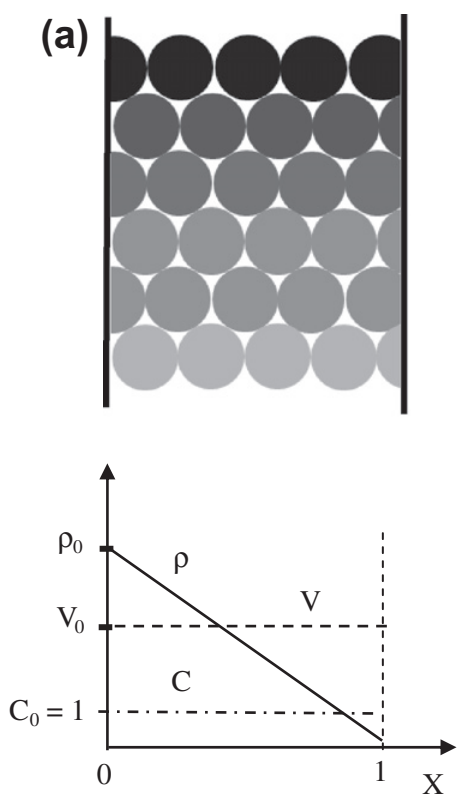

(b)
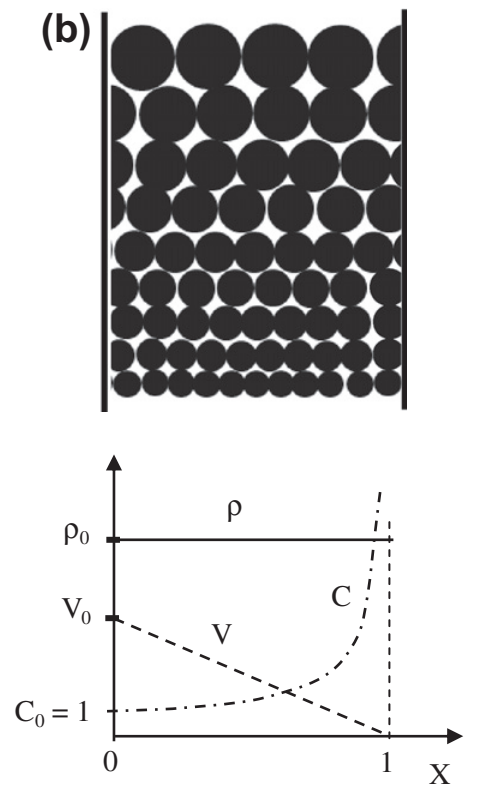

Fig. 8. Evolution during conversion of density and velocity of a char bed of monodisperse particles in two ideal situations for particle reaction: (a) uniform conversion and (b) surface conversion.

case of a uniform conversion, there is no compaction ( $C$ is constant) because particle size remains constant: char bed density decreases linearly from its initial value to 0 at $100 \%$ of conversion and velocity remains constant. In the case of surface conversion, the reduction in particle size during conversion induces a linear decrease of velocity from its initial value to 0 at $100 \%$ of conversion. In the case of a bed with mono size spheres for which the inter particle porosity re mains unchanged, char bed density remains constant. Conse quently, the compaction increases during conversion from 1 to infinity according to the following equation.

C $\frac{1}{1 \quad X}$

These two situations will be considered as references in the fol lowing discussion.

Using Fig. 9, we now compare the compaction as calculated from experiments with a WCC bed and a WPC bed over the conver sion profile. On both graphs, three curves are plotted for each feed stock because three independently measured conversion profiles were obtained (see Section 3.2). For the char at the surface of the bed $(X \quad 0 \%)$ and the first sample close to the surface $(X \sim 70 \%)$, we plotted the two curves showing the evolution of compaction following uniform and surface conversion models.

The graph at the top of Fig. 9 shows the compaction of the WCC bed over conversion. In the first $70 \%$ of conversion, compaction reaches about $2.1(z \sim 3 \mathrm{~cm})$. In the zone after $70 \%$ conversion, where most of the experimental points are available, compaction increases to 6 at about 95\% conversion $(z \sim 44 \mathrm{~cm})$.

The graph at the bottom of Fig. 9 shows the compaction of the WPC bed over conversion. Again, in the zone before $70 \%$ conversion, compaction reaches about 2.1 . In the zone after $70 \%$ conversion, compaction increases to reach 7.6 at $95 \%(z \sim 18 \mathrm{~cm})$.

Under these operating conditions our preliminary conclusions are as follows:

In the first zone below about $70 \%$ conversion, neither a uniform conversion model nor a surface conversion model can predict char bed compaction. More sophisticated models are required.
In the zone after $70 \%$ conversion, the evolution of compaction over conversion is very close to a surface conversion model. The surface conversion model can be considered appropriate for predicting char bed compaction in this zone and could be applied to global models.

These conclusions are valid for both a low density char (as WCC) and a high density char (as WPC).
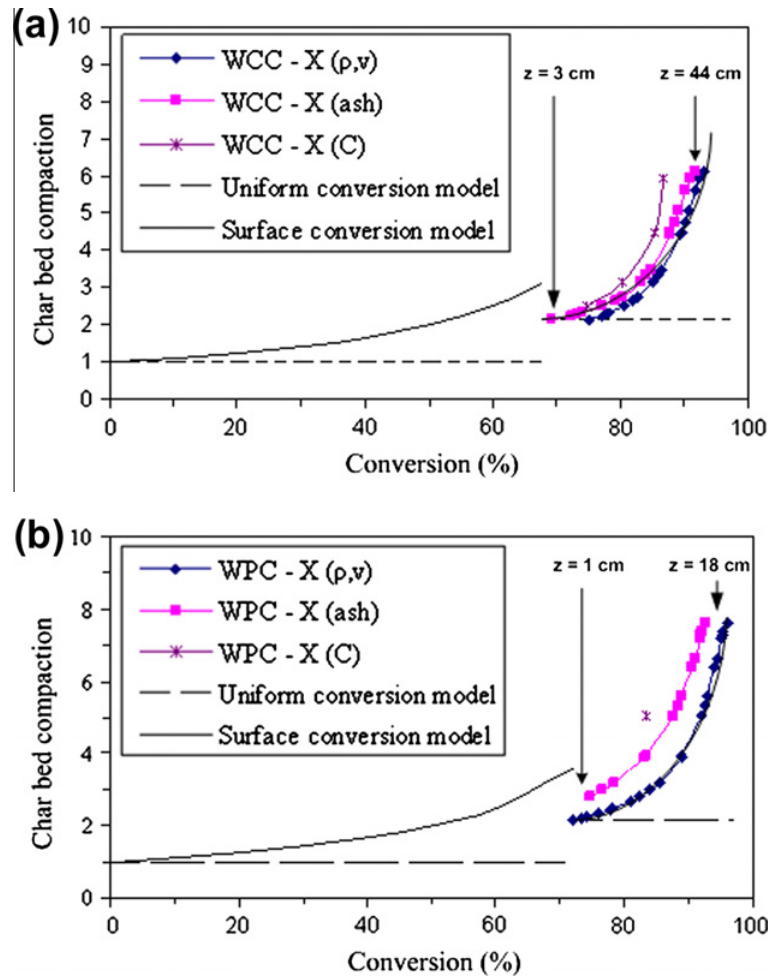

Fig. 9. Char bed compaction versus conversion for WCC bed (a) and WPC bed (b). 
Table 3

Factors/phenomena impacting on compaction for a WCC and a WPC bed.

\begin{tabular}{lll}
\hline & WCC & WPC \\
\hline Size reduction due to surface conversion & + & ++ \\
Fragmentation & & \\
Mechanical fragility: -initial porosity & + & - \\
$\quad$ - porosity increase due to conversion & + & - \\
$\quad$ structure (break plan) & + & - \\
Static pressure of char bed weight & - & - \\
Frictions between particles & - & - \\
Particles re-arrangement & + & - \\
\hline
\end{tabular}

Nevertheless, we believe that such simple models fail to provide a satisfactory description of the process, which is much more com plex. Indeed, many other phenomena can affect compaction. They are listed in Table 3. Below, we discuss and compare each phenom enon depending on whether a WCC bed or a WPC bed is considered.

\subsubsection{Size reduction due to surface conversion}

If the WCC bed is considered, the impact of size reduction on compaction appears small. Indeed, in two previous studies $[21,22]$, we have shown that the conversion regime for char parti cles was close to the uniform one and that particle size remained constant up to a level of $60 \%$ conversion in the operating conditions considered $\left(T<1100{ }^{\circ} \mathrm{C}\right.$ and $\left.P_{\mathrm{H} 2 \mathrm{O}}<30 \%\right)$. We also showed that be yond $60 \%$ conversion, the reduction in particle diameter was caused more by fragmentation than conversion.

For a WPC bed, given the high density of WPC particles, it is likely that conversion occurs in a regime close to a diffusion lim ited regime, with a decrease in particle size along conversion. Con sequently, we believe that the reduction in particle size due to conversion has a greater impact on compaction for WPC than for WCC (as shown by the number of + signs in Table 3 ).

Moreover, at the top of the bed and for both char beds, the pres ence of oxygen in the gasifying stream can favor compaction be cause char oxidation progresses in a surface conversion regime for the level of temperatures considered [20]. In a previous study, we showed that in our operating conditions $\left(3 \% \mathrm{O}_{2}\right.$ in the gasifying stream), char oxidation was responsible for about $13 \%$ of the con version [17]. Consequently, compaction due to oxidation is insig nificant here because it will increase $C$ to only about 1.15 (Eq. (5)).

\subsubsection{Fragmentation}

Fragmentation of particles can also play a major role in compac tion by affecting the particle size distribution and inter particle porosity. Fragmentation is due to the mechanical fragility of the char particles. The static pressure on the particles caused by the char bed weight above and the friction between particles or be tween particles and the reactor wall also contribute to fragmentation.

Mechanical fragility, as shown in Table 3, is conditioned by intra particle porosity and by the structure of the char particles. Initial particle porosities are 0.74 and 0.51 for WCC and WPC, respectively: the impact of this criterion on compaction is greater in the case of a WCC bed. Moreover, the conversion regime has an impact on the evolution of intra particle porosity during conversion. Indeed, the closer the conversion regime is to the uniform one (Fig. 8a) the greater the increase in porosity with conversion and, in turn, the higher the potential for frag mentation because particles become progressively weaker. Therefore, the increase in porosity is greater for WCC particles than for WPP. As a result, WCC particles are more fragile during conversion.
The last criterion that has an impact on mechanical fragility is the initial structure of the biomass. A fibrous material, such as WCC, has longitudinal break plans (i.e. along the fibers). Therefore, it is more likely to fragment than a homogenously compacted material, such as the WPC, which is very hard.

Static pressure (Eq. (6)) caused by the weight of the char bed can affect fragmentation. Indeed, as particles progress along the reactor, the static pressure increases and so does the poten tial for fragmentation. The static pressure along the char parti cle bed can be calculated as follows:

$$
P(z) \quad \int_{0}^{z} \rho(z) g d z
$$

Using our measurements for bed density profiles along the bed, we have plotted the profiles of static pressure along the char bed for both feedstocks in Fig. 10. The static pressure along the bed is always higher (about 3 times) for the WPC bed at a given height it is likely to have a greater impact on fragmentation. This is be cause the density of the WPC bed is 3 times higher than the density of the WCC bed. Nevertheless, at a given conversion the static pres sure of both beds is similar because the lower density of the WCC bed is compensated for by a greater char bed height. As a result, in the range $095 \%$ of conversion, static pressure would have the same impact on fragmentation and compaction no matter which char is considered.

Friction is thought to affect fragmentation if the velocity of the char flow is high. This seems unlikely in our study because the maximum char particle velocity is about 7 and $3 \mathrm{~mm} \mathrm{~min}{ }^{1}$ for WCC and WPC, respectively.

\subsubsection{Re arrangement of particles}

The re arrangement of particles in the reactor during particle descent may encourage compaction. The phenomenon is encour aged by the polydispersion of particle size and shape. We remind that a monosize spherical particle bed always presents inter parti cle porosity of about 0.4 . Here, WCC particles demonstrate greater polydispersion and, therefore, are more likely to be affected by re arrangement.

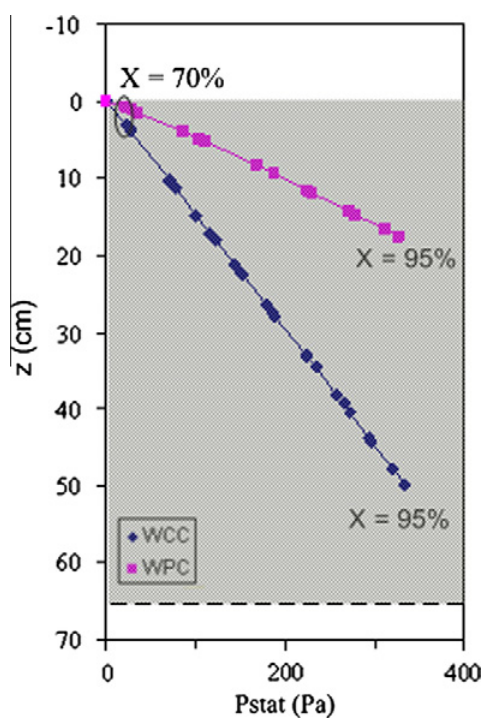

Fig. 10. Profiles of static pressure along the bed for WCC and WPC. 
To sum up, char bed compaction is similar overall for both char beds although the phenomena may be quantitatively different. On analysis of the + and signs in Table 3, compaction is thought to be controlled by:

(i) particle fragility, which increases during conversion for the low density char;

(ii) the conversion regime close to the surface reaction, for the high density char.

Nevertheless, it is important to remember that these complex phenomena are linked and, therefore, difficult to observe sepa rately. In the light of current knowledge, it is not possible to prior itize them quantitatively in terms of their impact on compaction.

\section{Conclusions}

Wood char gasification in continuous downdraft fixed bed reac tors has been investigated experimentally using the specially developed CFiB reactor. Measurements of profiles along the char bed for temperature, gas species concentration, char composition, char bed density and particle velocity were taken using fine instru mentation, specific char and gas sampling techniques, as well as sample analysis.

As far as methodology is concerned, we showed that char bed conversion along the reactor can be calculated satisfactorily using three independent methods: ash content of the solid, carbon mass balance based on gas phase analysis or measurements of the bulk density of both char beds and char velocity.

Pelletization as compared to using wood chips has no effect on final char conversion and syngas quality. On the contrary, the reactive zone of the char bed, where the outlet char conversion is reached, is 3 times greater for chips $(45 \mathrm{~cm})$ than for pellets $(16 \mathrm{~cm})$. Consequently, the use of pellets could lead to a significant reduction in the reactor length of industrial gasifiers.

In the continuous fixed bed reactor, we distinguished two zones in the char bed. First, a highly reactive zone of about $4 \mathrm{~cm}$ thick within which values for all the parameters that were measured changed considerably: $70 \%$ conversion is reached, char velocity and char bed density decreases by $57 \%$ and $47 \%$, respectively, and $90 \%$ of $\mathrm{H}_{2}$ and $\mathrm{CO}$ is produced. Below, there is a larger zone where the parameters that were measured changed slowly.

Bed compaction, which is defined as the ratio between initial and in progress char particle velocities, is similar for wood chips and wood pellets. For both feedstocks, an intermediary conversion model for particle reaction should be considered so that char bed compaction before $70 \%$ conversion can be predicted. After 70\%, a surface conversion model can accurately predict char bed compac tion. For WCC, char bed compaction is attributed to the greater fra gility of char particles, which increases during conversion. For WPC, compaction is attributed to the reduction in particle size caused by the conversion regime close to the surface reaction.

Finally, the overall results presented in this paper provide a new database that can be used to help develop or validate numerical models of the char bed gasification zone for fixed bed or two stage gasifiers.

\section{References}

[1] Bridgwater AV. Renewable fuels and chemicals by thermal processing of biomass. Chem Eng J 2003;91(2-3):87-102.

[2] Henriksen U, Ahrenfeldt J, Jensen TK, Gøbel B, Bentzen JD, Hindsgaul C, et al. The design, construction and operation of a $75 \mathrm{~kW}$ two-stage gasifier. Energy 2006;31(10-11):1542-53 [ECOS 2003].

[3] Berger B, Bacq A, Jeanmart H, Bourgois F. Experimental and numerical investigation of the air ratio on the tar content in the syngas of a two-stage gasifier. In: 19th European biomass conference and exhibition (19th EU BC\&E), Lyon; 2010. p. 20-5.

[4] Lal R. World crop residues production and implications of its use as a biofuel. Environ Int 2005;31(4):575-84.

[5] Bentzen JD, Hindsgaul C, Henriksen UB, Sørensen LH. Straw gasification in a two-stage gasifier. In: Proceeding of the 12th European conference and technology exhibition on biomass for energy, industry and climate protection, Amsterdam; June 2002. p. 577.

[6] Erlich C, Björnbom E, Bolado D, Giner M, Fransson TH. Pyrolysis and gasification of pellets from sugar cane bagasse and wood. Fuel 2006;85(1011):1535-40

[7] Lehtikangas P. Storage effects on pelletised sawdust, logging residues and bark. Biomass Bioenergy 2000;19(5):287-93.

[8] Krishnudu T, Madhusudhan B, Reddy SN, Sastry VSR, Rao KS, Vaidyeswaran R. Studies in a moving bed pressure gasifier: prediction of reaction zones and temperature profile. Ind Eng Chem Res 1989;28(4):438-44.

[9] Lv P, Yuan Z, Ma L, Wu C, Chen Y, Zhu J. Hydrogen-rich gas production from biomass air and oxygen/steam gasification in a downdraft gasifier. Renew Energy 2007;32(13):2173-85

[10] Di Blasi C, Signorelli G, Portoricco G. Countercurrent fixed-bed gasification of biomass at laboratory scale. Ind Eng Chem Res 1999;38:2571-81.

[11] Na JI, Park SJ, Kim YK, Lee JG, Kim JH. Characteristics of oxygen-blown gasification for combustible waste in a fixed-bed gasifier. Appl Energy 2003;75(3-4):275-85

[12] Yang W, Ponzio A, Lucas C, Blasiak W. Performance analysis of a fixed-bed biomass gasifier using high-temperature air. Fuel Process Technol 2006;87(3):235-45.

[13] Erlich C, Fransson TH. Downdraft gasification of pellets made of wood, palmoil residues respective bagasse: experimental study. Appl Energy 2011;88(3):899-908.

[14] Di Blasi C. Modeling wood gasification in a countercurrent fixed-bed reactor. AIChE J 2004;50(9):2306-19.

[15] Gobel B, Bentzen JD, Hindsgaul C, Henriksen U, Ahrenfeldt J, Houbak N, et al. High performance gasification with the two-stage gasifier. In: Proceedings of the 12th European conference and technology exhibition on biomass for energy, industry and climate protection, Amsterdam; 2002. p. 389-95.

[16] Barrio M. Experimental investigation of small-scale gasification of woody biomass. Doctorate thesis, Norwegian University of Science and Technology (NTNU), Trondheim, Norway; 2002.

[17] Van de steene L, Tagutchou JP, Mermoud F, Martin E, Salvador S. A new experimental continuous fixed bed reactor to characterise wood char gasification. Fuel 2010;89(11):3320-9.

[18] Fassinou WF, Van de Steene L, Toure S, Volle G, Girard P. Pyrolysis of Pinus pinaster in a two-stage gasifier: influence of processing parameters and thermal cracking of tar. Fuel Process Technol 2009;90(1):75-90.

[19] Mermoud F, Salvador S, Van de Steene L, Golfier F. Influence of the pyrolysis heating rate on the steam gasification rate of large wood char particles. Fuel 2006;85(10-11):1473-82.

[20] Van de steene L, Tagutchou JP, Escudero Sanz FJ, Salvador S. Gasification of woodchip particles: experimental and numerical study of char- $\mathrm{H}_{2} \mathrm{O}$, char- $-\mathrm{CO}_{2}$, and char- $\mathrm{O}_{2}$ reactions. Chem Eng Sci 2011;66(20):4499-509.

[21] Tagutchou JP. Gazéification du charbon de plaquettes forestières: particule isolée et lit fixe continu. Thèse de Doctorat, Université de Perpignan; 2008.

[22] Mermoud F, Golfier F, Salvador S, Van de Steene L, Dirion JL. Experimental and numerical study of steam gasification of a single charcoal particle. Combust Flame 2006;145(1-2):59-79. 